Provided for non-commercial research and education use. Not for reproduction, distribution or commercial use.

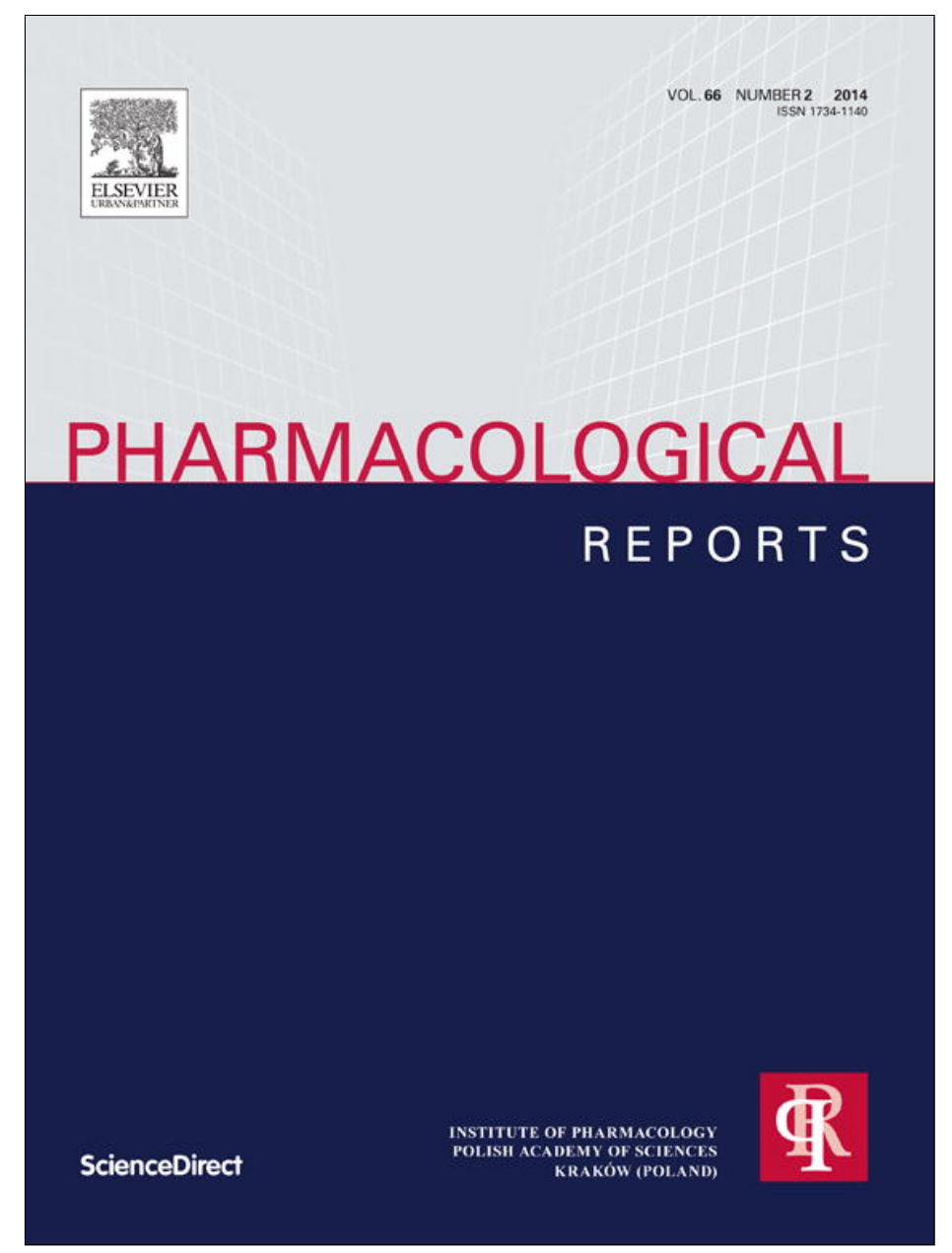

This article appeared in a journal published by Elsevier. The attached copy is furnished to the author for internal non-commercial research and education use, including for instruction at the authors institution and sharing with colleagues.

Other uses, including reproduction and distribution, or selling or licensing copies, or posting to personal, institutional or third party websites are prohibited.

In most cases authors are permitted to post their version of the article (e.g. in Word or Tex form) to their personal website or institutional repository. Authors requiring further information regarding Elsevier's archiving and manuscript policies are encouraged to visit:

http://www.elsevier.com/authorsrights 
Original research article

\title{
Effects of liposomes with polyisoprenoids, potential drug carriers, on the cardiovascular and excretory system in rats
}

\author{
Olga Gawrys ${ }^{\mathrm{a}}$, Marta Polkowska a , Malwina Roszkowska-Chojecka ${ }^{\mathrm{a}}$, Katarzyna Gawarecka ${ }^{\mathrm{b}}$,

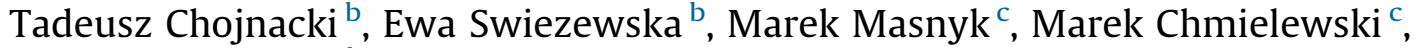 \\ Janina Rafałowska ${ }^{\mathrm{d}}$, Elżbieta Kompanowska-Jezierska ${ }^{\mathrm{a}, *}$ \\ a Department of Renal and Body Fluid Physiology, M. Mossakowski Medical Research Centre, Polish Academy of Sciences, Warsaw, Poland \\ ${ }^{\mathrm{b}}$ Department of Lipid Biochemistry, Institute of Biochemistry and Biophysics, Polish Academy of Sciences, Warsaw, Poland \\ ${ }^{\mathrm{c}}$ Institute of Organic Chemistry, Polish Academy of Sciences, Warsaw, Poland \\ ${ }^{\mathrm{d}}$ Department of Experimental and Clinical Neuropathology, M. Mossakowski Medical Research Centre, Polish Academy of Sciences, Warsaw, Poland
}

\section{A R T I C L E I N F O}

\section{Article history:}

Received 4 April 2013

Received in revised form 3 September 2013

Accepted 12 September 2013

Available online 3 March 2014

\section{Keywords:}

Liposomes

Drug delivery

Polyisoprenoid alcohols

Renal toxicity

Renal morphology
A B S T R A C T
Background: The unpredictable side effects of a majority currently used drugs are the substantial issue, in
which patients and physicians are forced to deal with. Augmenting the therapeutic efficacy of drugs may
prove more fruitful than searching for the new ones. Since recent studies show that new cationic
derivatives of polyisoprenoid alcohols (APrens) might exhibit augmenting properties, we intend to use
them as a component of liposomal drug carriers. In this study we investigate if these compounds do not
per se cause untoward effects on the living organism.
Methods: Male Sprague-Dawley rats received for four weeks daily injections ( $0.5 \mathrm{ml} s c$ ) of liposomes
built of dioleoyl phosphatidylethanolamine (DOPE), liposomes built of DOPE and APren-7 (ratio 10:1) or
water solvent. Weekly, rats were observed in metabolic cages ( $24 \mathrm{~h}$ ); blood and urine were sampled for
analysis; body weight (BW) and systolic blood pressure (SBP) were determined. After chronic
experiment, kidneys and heart were harvested for histological and morphometric analysis.
Results: The 4 -week BW increments were in the range of $97 \pm 4$ to $102 \pm 4 \%$ intergroup differences were
not significant. Microalbuminuria was the lowest in the group receiving liposomes with APren-7
(0.22 \pm 0.03 mg/day). Water and food intake, plasma and urine parameters were similar in all groups.
Conclusions: Newly designed liposomes containing APren-7 did not affect functions of the excretory and
cardiovascular systems, and renal morphology; therefore we find them suitable as a component of
liposomal drug carriers.
○ 2014 Institute of Pharmacology, Polish Academy of Sciences. Published by Elsevier Urban \& Partner Sp. $\mathrm{z}$ o.o. All rights reserved.

\section{Introduction}

A majority of currently used drugs display, in addition to the therapeutic action, definite side effects which are often severe and unpredictable; the difference between the therapeutic and

Abbreviations: APren, cationic derivative of polyisoprenoid alcohol; BW, body weight; DDS, drug delivery systems; DOPE, dioleoyl phosphatidylethanolamine; DPPC, dipalmitoylphosphatidylcholine; Ht, haematocrit; LV/BW, left ventricular to - body weight ratio; $\mathrm{NO}$, nitric oxide; $\mathrm{NO}_{\mathrm{x}}$, excretion of nitric oxide metabolites; PE, phosphatidylethanolamine; $\mathrm{P}_{\mathrm{Na}}$, plasma sodium concentration; $\mathrm{P}_{\mathrm{osm}}$, plasma osmolality; SBP, systolic blood pressure; $s c$, subcutaneously; UAE, urinary albumin excretion; $U_{K}$, concentration of potassium in urine; $U_{\mathrm{Na}}$, concentration of sodium in urine; $\mathrm{U}_{\mathrm{osm}}$, urine osmolality.

* Corresponding author.

E-mail address: ellakomp@gmail.com (E. Kompanowska-Jezierska). harmful dose may be quite small. This may necessitate monitoring drug concentration in the patient's serum, which is cumbersome and increases the cost of treatment [9]. In light of the recent literature of the subject, a search for substances which augment the therapeutic efficacy of existing drugs may prove equally fruitful as the development of the new ones. Drug delivery systems (DDS) which include many different conjugates, such as polymeric micelles, liposomes, hybrid carriers and polyplexes (complexes of the polymer-DNA type) [1,4] may provide better penetration of drugs across biological membranes which results in faster access to the interior of cells and, in general, to areas distant from the lumen of blood vessels. Currently, liposomal formulations which facilitate the penetration through biological membranes are widely used as carriers of pharmacologically active substances [24]. Cationic lipids of various structures have been suggested to enhance the 
efficacy of liposomal drug and nucleic acids delivery [14,21]. Recent studies show that cationic derivative of polyprenol tentatively named APren, new semi-synthetic derivative of polyisoprenoid alcohol, might be successfully used as component of liposomal formulas used for lipofection [18].

Polyprenols are linear polymers built of 5 up to 150 isoprene units. Their postulated cellular functions comprise involvement in cell response to environmental stress [26]. It is known that polyprenols and their phosphorylated derivatives increase the permeability and fluidity of model membranes and intensify the fusion of model membranes [26]. A new type of semi-synthetic cationic polyisoprenoid derivatives has been obtained recently. Taking advantage of their lipofecting properties [18] new drug carriers based on liposomes containing these derivatives of polyisoprenoid alcohols were designed. From among various naturally occurring polyprenols, the one containing seven isoprene units was subjected to chemical modifications to obtain heptaprenyltrimethylammonium iodide (APren-7), to be used as a component of liposomal drug carrier. Our aim was to investigate if this compound does not per se cause untoward effects on the living organism.

Among mammalian organs and tissues the kidneys are known to be particularly sensitive to drug-dependent toxicity which may damage the renal glomeruli and various structures and tissues located in the renal medulla, such as local tubule fragments, interstitium and vasa recta. The vulnerability of the medulla obviously depends on the usual process of concentration of numerous substances, including various drugs, which occurs in this region. In this study we focused on potential changes in kidney structure and function but also examined some indices of general health and behaviour (e.g. weight gain, activity) as well as selected status indices of the cardiovascular system.

The impact of APren-7 on living organisms was studied in male Sprague-Dawley rats; animals aged 5-6 weeks were used to determine, in addition, the possible influence of APren-7 on the development and maturation. Effects of subcutaneous injections of liposomes containing APren-7 were compared with those of liposomes built exclusively of commonly used dioleoyl phosphatidylethanolamine (DOPE), and those seen in rats receiving water solvent for liposome solutions.

\section{Materials and methods}

\section{Preparation of heptaprenyltrimethylammonium iodide (APren-7)}

This compound was obtained by modification of polyisoprenoid alcohols derived from birch wood following the procedure described earlier [18].

\section{Preparation of liposomal suspensions for injection}

Liposomal suspensions were prepared using lipid film hydration protocol. Briefly, to obtain classical liposomes $(L), 55 \mu \mathrm{l}$ of a solution of 1,2-dioleoyl-sn-glycero-3-phosphoethanolamine (DOPE, Sigma) in chloroform $(90 \mathrm{mg} / \mathrm{ml})$ was dried by stream of nitrogen gas to form a thin film on the bottom of the glass tube. The film was further dried by exsiccation under reduced pressure, overnight. Then water was added to hydrate the film and multilamellar liposomes were formed by vortexing each tube for at least $8 \mathrm{~min}$. The obtained suspension was extruded few times through a $100 \mathrm{~nm}$ membrane to obtain unilamellar liposomes (LiposoFast extruder, Avestin Europe GmbH, Mannheim, Germany).

To obtain liposomes with APren-7 $(\mathrm{L}+\mathrm{P}), 50 \mu \mathrm{l}$ of a solution of DOPE in chloroform $(90 \mathrm{mg} / \mathrm{ml})$ and $25 \mu \mathrm{l}$ of a solution of APren-7 in chloroform $(18 \mathrm{mg} / \mathrm{ml})$ were mixed together (DOPE:APren-7 molar ratio 10:1) and then the procedure of further preparation was as described above.

\section{Experimental animals}

The experimental procedures were approved by the IV Ethical Committee, Warsaw. Male Sprague-Dawley rats, weighing $154 \pm 3 \mathrm{~g}$ at the start of experiments, were fed ad libitum a standard $\operatorname{diet}$ (STD, $0.25 \% \mathrm{Na} w / \mathrm{w}$, SSNIFF GmbH, Soest, Germany) and had free access to drinking water during the whole experiment. The animals were accustomed to the housing and measurement procedures during the week preceding the experiments. This was done to eliminate the stress associated with immobilization needed to measure systolic blood pressure (SBP); such stress is known to increase SBP per se.

\section{Experimental protocols and measurements}

During four weeks three groups of rats received daily injections $(0.5 \mathrm{ml}, \mathrm{sc})$ of freshly prepared solutions of classical liposomes (L, $n=13$ ), liposomes with APren-7 ( $\mathrm{L}+\mathrm{P}, n=13,12 \mathrm{mg} / \mathrm{kg})$, or water solvent $(\mathrm{W}, n=12)$. At one-week intervals rats were placed for $24 \mathrm{~h}$ in metabolic cages (Tecniplast S.p.A. Buguggiate, Italy) to measure food and water intake, the weight of faeces, and urine volume and osmolality $\left(\mathrm{U}_{\mathrm{osm}}\right)$, as well as the concentration of sodium $\left(\mathrm{U}_{\mathrm{Na}}\right)$, potassium $\left(\mathrm{U}_{\mathrm{K}}\right)$, albumin and nitric oxide metabolites. Also determined were body weight (BW) and SBP (tail-cuff method, Coda System, Kent Scientific Corporation, Connecticut, USA); blood was sampled for plasma osmolality $\left(\mathrm{P}_{\mathrm{osm}}\right)$, plasma sodium concentration $\left(\mathrm{P}_{\mathrm{Na}}\right)$ and haematocrit $(\mathrm{Ht})$. In the end of the experiment all animals were anesthetized with intraperitoneal sodium thiopental (Sandoz GmbH, Kundl, Austria), $100 \mathrm{mg} / \mathrm{kg}$, and the samples of the kidneys (for morphometric and histologic studies) and of the heart (for morphometric examination only) were harvested.

\section{Analytical procedures}

Urine volume was determined by gravimetric method, plasma and urine osmolality by freezing point depression (Osmomat ${ }^{\mathbb{R}}$ 030 M, Gonotec, Berlin, Germany), sodium and potassium concentration by flame photometry (PFP7/C, Jenway Ltd, Stone, UK), nitrites/nitrates using nitric oxide (total) detection kit (Enzo Life Sciences Inc., New York, USA), and albumin content using UAE immunoperoxidase assay for determination of albumin in rat samples (Immunology Consultants Laboratory, Inc., Portland, USA).

\section{Statistics}

Data are presented as means \pm SEM. The significance of changes was evaluated by multivariate analysis of variance (ANOVA) with repeated measurements, followed by Newman-Keuls post hoc test (STATISTICA, version 10.0, StatSoft Inc.). The 4-week increments in the parameters measured were compared between groups by oneway ANOVA. The level of statistical significance was set at of $p<0.05$.

\section{Results}

Body weight profiles over 4 weeks are shown in Fig. 1. The increase of the body mass was almost parallel for all three groups of animals analyzed. When expressed as per cent of the starting weight value (unlike in Fig. 1. where absolute values are given), the curves for L, L + P and $\mathrm{W}$ groups were superimposable. The 4-week BW increments were $109 \pm 4,97 \pm 4$ and $102 \pm 4 \%$ in the respective groups (intergroup differences not significant).

Water and food intake, faeces weight, and urine volume, total solute, sodium and potassium excretion in four consecutive weeks are presented in Table 1. For most of the parameters measured the starting values (week 0 ) tended to be slightly higher in animals 


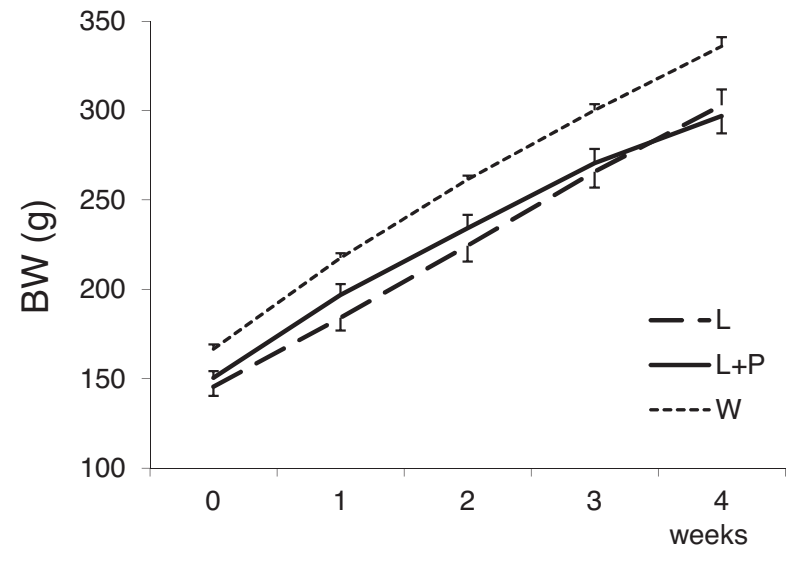

Fig. 1. Four-week profiles of body weight (BW) of rats receiving: $\mathrm{L}-$ liposomes built of DOPE $(n=13), \mathrm{L}+\mathrm{P}$ - liposomes built of DOPE and APren-7 $(n=13), \mathrm{W}$ - water $(n=12)$.

receiving water solvent compared to those of the two liposome treated groups and the differences were maintained throughout the 4-week observation period. The intergroup differences in total 4-week increments in water intake and urine volume deserve attention. The increment $(\Delta)$ of water intake was in the two liposome treated groups distinctly lower than in the $\mathrm{W}$ group; the difference was significant for the $\mathrm{L}+\mathrm{P}$ group only (last column of Table 1). On the other hand, the increment of urine volume in liposome treated groups was higher than in the $\mathrm{W}$ group (difference significant for the $L$ group).

Systolic blood pressure (SBP) slightly increased in each group during four weeks of observation: in group L from $131 \pm 3$ to $135 \pm 3 \mathrm{mmHg}$, in $\mathrm{L}+\mathrm{P}$ from $129 \pm 4$ to $144 \pm 5 \mathrm{mmHg}$, and in $\mathrm{W}$ from $131 \pm 7$ to $142 \pm 4 \mathrm{mmHg}$ (non-significant, Fig. 2). The variability of SBP data was relatively high and there were no significant within-group or inter-group differences.

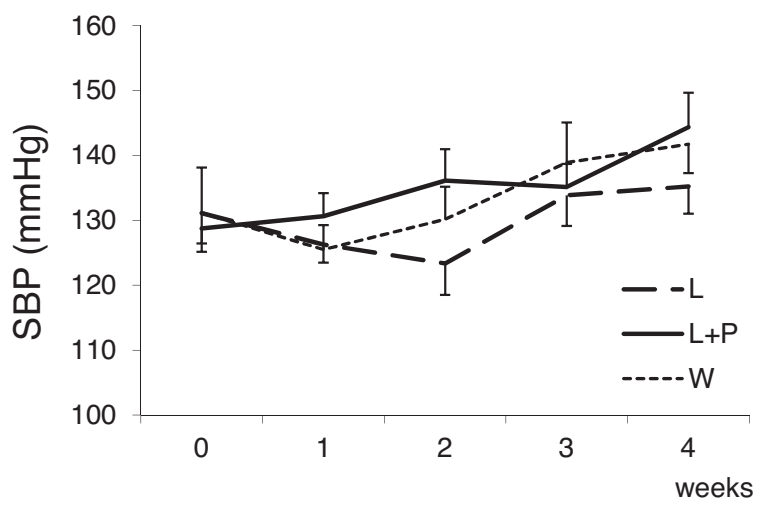

Fig. 2. Four-week profiles of systolic blood pressure (SBP) in rats receiving: $\mathrm{L}$ liposomes built of DOPE $(n=8), \mathrm{L}+\mathrm{P}-$ liposomes built of DOPE and APren-7 $(n=8)$, W - water $(n=8)$.

Plasma osmolality, sodium concentration and blood haematocrit did not show significant changes over time (within groups) or between experimental groups (Table 2).

Urinary albumin excretion (UAE) measurements before treatments and in the last week of observation (Fig. 3) disclosed a significant increase in W group only; in the fourth week UAE in this group was significantly higher than in groups $\mathrm{L}$ and $\mathrm{L}+\mathrm{P}$.

The excretion of nitric oxide metabolites (nitrites/nitrates, $\mathrm{NO}_{\mathrm{x}}$ ) measured before and in the fourth week of treatments disclosed no significant within-group (time dependent) or inter-group differences (Fig. 4).

Left ventricular - to - body weight ratio (LV/BW), measured in each animal at the end of the experiments, was the highest in the $\mathrm{L}$ group and significantly different from that in the $\mathrm{W}$ but not in the $\mathrm{L}+\mathrm{P}$ group (Fig. 5). The values for $\mathrm{L}$ and $\mathrm{L}+\mathrm{P}$ groups were not significantly different.

Table 1

Four-week profiles of daily water and food intake, urine volume, total solute, sodium and potassium excretion in the three groups.

\begin{tabular}{|c|c|c|c|c|c|c|c|}
\hline & \multirow[t]{2}{*}{ Group } & \multicolumn{5}{|c|}{ Weeks } & \multirow{2}{*}{$\begin{array}{c}\Delta \\
0-4\end{array}$} \\
\hline & & 0 & 1 & 2 & 3 & 4 & \\
\hline Water intake $(\mathrm{ml} / 24 \mathrm{~h})$ & $\begin{array}{l}\mathrm{L} \\
\mathrm{L}+\mathrm{P} \\
W\end{array}$ & $\begin{array}{l}21 \pm 1 \\
24 \pm 1 \\
23 \pm 1\end{array}$ & $\begin{array}{l}23 \pm 2 \\
25 \pm 1 \\
27 \pm 1\end{array}$ & $\begin{array}{l}23 \pm 1 \\
27 \pm 1 \\
29 \pm 1\end{array}$ & $\begin{array}{l}25 \pm 1 \\
26 \pm 2 \\
30 \pm 1\end{array}$ & $\begin{array}{l}27 \pm 2 \\
29 \pm 2 \\
37 \pm 3\end{array}$ & $\begin{array}{r}6 \pm 2 \\
4 \pm 2 \\
13 \pm 3\end{array}$ \\
\hline Food intake (g/24h) & $\begin{array}{l}\mathrm{L} \\
\mathrm{L}+\mathrm{P} \\
W\end{array}$ & $\begin{array}{l}14.2 \pm 0.8 \\
16.0 \pm 0.7 \\
17.2 \pm 0.5\end{array}$ & $\begin{array}{l}16.3 \pm 1.0 \\
16.9 \pm 1.0 \\
18.8 \pm 0.7\end{array}$ & $\begin{array}{l}17.2 \pm 0.8 \\
17.9 \pm 1.7 \\
20.2 \pm 1.3\end{array}$ & $\begin{array}{l}18.5 \pm 0.5 \\
16.2 \pm 0.7 \\
22.3 \pm 0.7\end{array}$ & $\begin{array}{l}19.1 \pm 0.9 \\
19.9 \pm 1.0 \\
21.4 \pm 0.9\end{array}$ & $\begin{array}{l}6.2 \pm 1.1 \\
3.9 \pm 1.2 \\
4.3 \pm 1.0\end{array}$ \\
\hline Faeces weight (g/24) & $\begin{array}{l}\mathrm{L} \\
\mathrm{L}+\mathrm{P} \\
\mathrm{W}\end{array}$ & $\begin{array}{l}5.1 \pm 0.4 \\
5.6 \pm 0.5 \\
6.8 \pm 0.5\end{array}$ & $\begin{array}{l}7.2 \pm 0.8 \\
7.4 \pm 0.7 \\
8.5 \pm 0.5\end{array}$ & $\begin{array}{l}6.7 \pm 0.8 \\
7.1 \pm 0.6 \\
8.4 \pm 0.7\end{array}$ & $\begin{array}{l}7.8 \pm 0.7 \\
7.4 \pm 0.6 \\
9.0 \pm 0.6\end{array}$ & $\begin{array}{r}7.2 \pm 0.7 \\
9.2 \pm 0.6 \\
10.7 \pm 0.6\end{array}$ & $\begin{array}{l}2.1 \pm 0.8 \\
3.6 \pm 0.8 \\
3.9 \pm 0.8\end{array}$ \\
\hline Urine volume (ml/24h) & $\begin{array}{l}\mathrm{L} \\
\mathrm{L}+\mathrm{P} \\
W\end{array}$ & $\begin{array}{l}5.1 \pm 0.4 \\
6.1 \pm 0.7 \\
7.0 \pm 0.5\end{array}$ & $\begin{array}{l}7.9 \pm 0.8 \\
8.1 \pm 0.4 \\
9.0 \pm 0.6\end{array}$ & $\begin{array}{l}7.3 \pm 0.7 \\
9.0 \pm 0.6 \\
8.4 \pm 0.6\end{array}$ & $\begin{array}{r}9.0 \pm 0.6 \\
9.1 \pm 1.0 \\
10.0 \pm 0.6\end{array}$ & $\begin{array}{l}10.9 \pm 0.6 \\
12.1 \pm 0.9 \\
11.0 \pm 0.5\end{array}$ & $\begin{array}{l}5.8 \pm 0.5^{*} \\
6.0 \pm 1.1 \\
3.9 \pm 0.6\end{array}$ \\
\hline Total solutes $(\operatorname{mosm} / 24 \mathrm{~h})$ & $\begin{array}{l}\mathrm{L} \\
\mathrm{L}+\mathrm{P} \\
W\end{array}$ & $\begin{array}{l}12.5 \pm 0.6 \\
12.8 \pm 1.0 \\
16.1 \pm 0.5\end{array}$ & $\begin{array}{l}17.0 \pm 0.9 \\
17.1 \pm 0.5 \\
20.1 \pm 0.4\end{array}$ & $\begin{array}{l}16.7 \pm 0.8 \\
17.5 \pm 0.6 \\
20.5 \pm 1.0\end{array}$ & $\begin{array}{l}20.0 \pm 0.7 \\
18.1 \pm 0.7 \\
22.7 \pm 0.9\end{array}$ & $\begin{array}{l}22.0 \pm 0.8 \\
21.8 \pm 0.7 \\
24.3 \pm 0.5\end{array}$ & $\begin{array}{l}9.5 \pm 1.1 \\
9.0 \pm 1.5 \\
8.2 \pm 0.9\end{array}$ \\
\hline $\mathrm{Na}^{+}(\mathrm{mmol} / 24 \mathrm{~h})$ & $\begin{array}{l}\mathrm{L} \\
\mathrm{L}+\mathrm{P} \\
\mathrm{W}\end{array}$ & $\begin{array}{l}0.7 \pm 0.0 \\
0.5 \pm 0.1 \\
0.9 \pm 0.0\end{array}$ & $\begin{array}{l}1.1 \pm 0.1 \\
0.8 \pm 0.1 \\
1.3 \pm 0.1\end{array}$ & $\begin{array}{l}1.0 \pm 0.1 \\
0.9 \pm 0.1 \\
1.5 \pm 0.1\end{array}$ & $\begin{array}{l}1.3 \pm 0.1 \\
1.0 \pm 0.1 \\
1.4 \pm 0.1\end{array}$ & $\begin{array}{l}1.4 \pm 0.1 \\
1.2 \pm 0.1 \\
1.6 \pm 0.1\end{array}$ & $\begin{array}{l}0.7 \pm 0.1 \\
0.7 \pm 0.1 \\
0.7 \pm 0.1\end{array}$ \\
\hline $\mathrm{K}^{+}(\mathrm{mmol} / 24 \mathrm{~h})$ & $\begin{array}{l}\mathrm{L} \\
\mathrm{L}+\mathrm{P} \\
\mathrm{W}\end{array}$ & $\begin{array}{l}3.1 \pm 0.2 \\
3.2 \pm 0.3 \\
4.0 \pm 0.1\end{array}$ & $\begin{array}{l}4.0 \pm 0.2 \\
3.8 \pm 0.1 \\
4.8 \pm 0.1\end{array}$ & $\begin{array}{l}3.5 \pm 0.2 \\
3.6 \pm 0.1 \\
4.7 \pm 0.2\end{array}$ & $\begin{array}{l}4.3 \pm 0.1 \\
3.8 \pm 0.2 \\
4.7 \pm 0.2\end{array}$ & $\begin{array}{l}4.6 \pm 0.2 \\
4.2 \pm 0.1 \\
4.9 \pm 0.2\end{array}$ & $\begin{array}{l}1.5 \pm 0.2 \\
1.0 \pm 0.3 \\
1.0 \pm 0.2\end{array}$ \\
\hline
\end{tabular}

Values are means \pm SEM; L - rats receiving liposomes $(n=13), \mathrm{L}+\mathrm{P}-$ liposomes with APren-7 $(n=13), \mathrm{W}-$ water solvent $(n=12)$.

$p<0.05$ vs. W group. 
Table 2

Four-week profiles of plasma osmolality and sodium concentration and blood haematocrit.

\begin{tabular}{|c|c|c|c|c|c|c|}
\hline & \multirow[t]{2}{*}{ Group } & \multicolumn{5}{|c|}{ Weeks } \\
\hline & & 0 & 1 & 2 & 3 & 4 \\
\hline \multirow[t]{3}{*}{ Plasma osmolality (mosm/l) } & $\mathrm{L}$ & $302 \pm 3$ & $299 \pm 2$ & $300 \pm 2$ & $306 \pm 1$ & $306 \pm 1$ \\
\hline & $\mathrm{L}+\mathrm{P}$ & $304 \pm 2$ & $301 \pm 2$ & $306 \pm 2$ & $310 \pm 2$ & $310 \pm 2$ \\
\hline & W & $300 \pm 1$ & $302 \pm 2$ & $307 \pm 1$ & $309 \pm 2$ & $307 \pm 3$ \\
\hline \multirow[t]{3}{*}{ Plasma sodium concentration (mmol/l) } & $\mathrm{L}$ & $136 \pm 2$ & $139 \pm 2$ & $133 \pm 2$ & $132 \pm 2$ & $133 \pm 1$ \\
\hline & $\mathrm{L}+\mathrm{P}$ & $130 \pm 1$ & $136 \pm 1$ & $132 \pm 2$ & $137 \pm 3$ & $129 \pm 2$ \\
\hline & W & $132 \pm 3$ & $134 \pm 2$ & $135 \pm 2$ & $131 \pm 2$ & $135 \pm 2$ \\
\hline \multirow[t]{3}{*}{ Haematocrit (\%) } & $\mathrm{L}$ & $40 \pm 1$ & $41 \pm 1$ & $43 \pm 0$ & $44 \pm 1$ & $43 \pm 1$ \\
\hline & $L+P$ & $40 \pm 0$ & $41 \pm 1$ & $42 \pm 1$ & $44 \pm 1$ & $42 \pm 1$ \\
\hline & W & $40 \pm 1$ & $41 \pm 1$ & $44 \pm 1$ & $44 \pm 1$ & $44 \pm 1$ \\
\hline
\end{tabular}

Values are means \pm SEM; rats receiving: $\mathrm{L}$ - liposomes $(n=13), \mathrm{L}+\mathrm{P}-$ liposomes with APren-7 ( $n=13), \mathrm{W}-$ water solvent $(n=12)$.

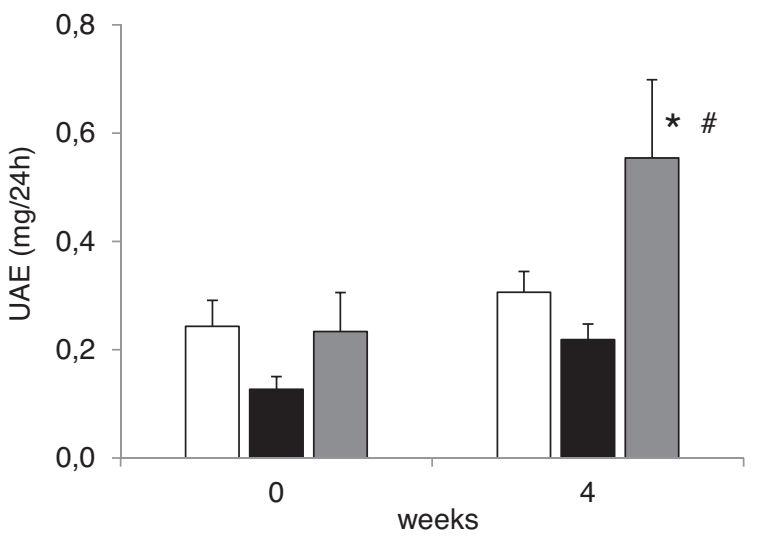

Fig. 3. Urinary albumin excretion (UAE, means \pm SEM) before and after 4 weeks of observation in rats receiving: $\square \mathrm{L}-$ liposomes $(n=7), \mathbf{L}+\mathrm{P}-$ liposomes with APren-7 $(n=7)$, $\square \mathrm{W}$ - water solvent $(n=6) ;{ }^{*} p<0.05$ vs. day "0"; $\# p<0.05$ vs. concurrent values in $\mathrm{L}$ and $\mathrm{L}+\mathrm{P}$ groups.

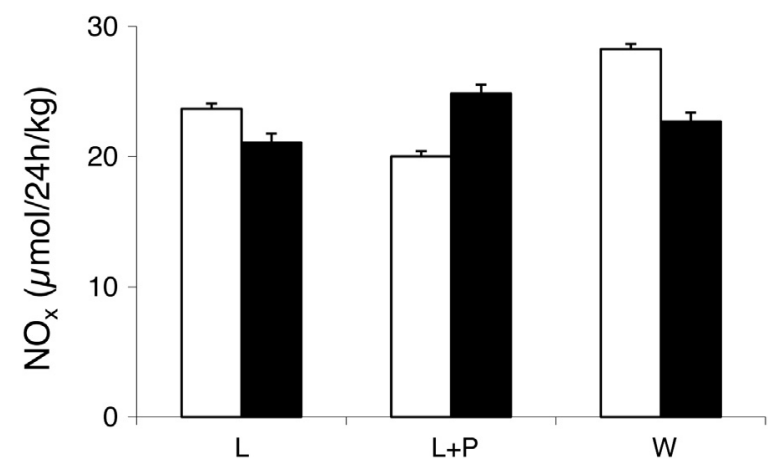

Fig. 4. Urinary excretion of nitric oxide metabolites $\left(\mathrm{U}_{\mathrm{NOx}} \cdot \mathrm{V}\right.$, means $\left.\pm \mathrm{SEM}\right) \square$ before and after four weeks of observation in rats receiving: $\mathrm{L}-$ liposomes $(n=7), \mathrm{L}+\mathrm{P}-$ liposomes with APren-7 $(n=6), \mathrm{W}$ - water solvent $(n=6)$.

Renal cortical and medullary tissue were harvested at the end of experiments and the slices were stained with haematoxylin-eosin (Fig. 6). There were no explicit signs of tissue damage in any experimental group. Nor were there any inter-group differences in the microscopic images of the renal cortex and medulla.

\section{Discussion}

Over the past decade, liposomal drug delivery systems were used by many researchers and various applications were reported, such as targeted gene therapy [11,25], transfollicular [15] or ophthalmic [20] drug delivery. In many cases DOPE (dioleoyl phosphatidylethanolamine), an analogue of the native PE with a defined fatty acid composition, was used in liposomal formulations. Due to its fusogenic properties DOPE is considered as valuable component of the lipofecting formulas. DOPE is not considered as toxic per se, however it has been shown to enhance the toxicity of various cationic lipids tested in the cell-line models since the replacement of DOPE by dipalmitoylphosphatidylcholine (DPPC) significantly reduced liposome toxicity towards macrophages [6]. Subsequently, new derivative of polyisoprenoid alcohol, the APren, was investigated in cell-line model [18] as potential component of liposomal drug carriers. A literature search shows that possible untoward effects of these compounds have never been tested before, therefore in the present study we address this issue, focusing on the impact of APren on some functional and morphologic features of the cardiovascular and renal excretory system of normal Sprague-Dawley rats.

All studied animals were in good health and displayed normal physical activity. In general, the parameters measured in the two groups receiving liposomes (the classical liposomes built of DOPE and the newly designed liposomes with DOPE and APren-7) were more similar to each other than to the group (W) receiving water solvent. There were no differences between groups regarding food intake, the renal excretion of total solute, sodium and potassium, or plasma osmolality and sodium concentration, and blood haematocrit.

It should be noted that the apparent between-group difference in absolute values of BW (Fig. 1) depended on higher baseline BW in the $\mathrm{W}$ group, obviously a matter of imperfect randomization of animals. Overall, the differences between groups were small and

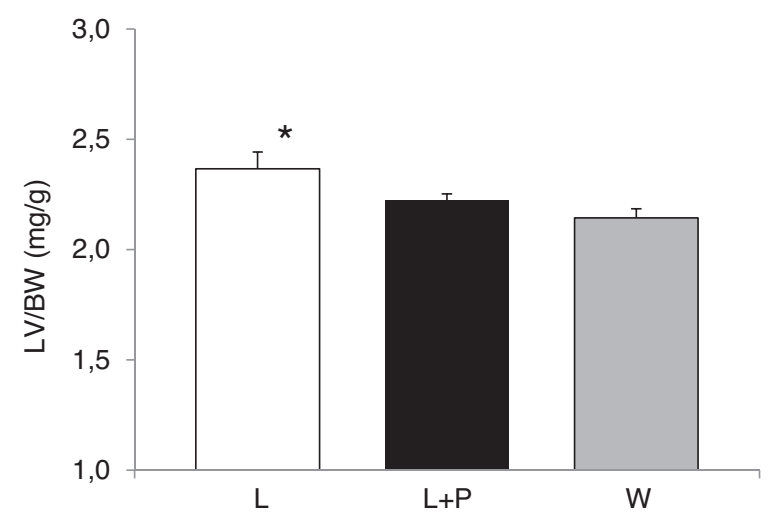

Fig. 5. Left ventricular weight to body weight ratio after 4 weeks of observation rats receiving: $\square \mathrm{L}-$ liposomes $(n=13), \mathbf{L}+\mathrm{P}-$ liposomes with APren-7 $(n=13), \square \mathrm{W}$ - water solvent $(n=16)$; ${ }^{*} p<0.05 v s$. W (one-way ANOVA followed by NewmanKeuls post hoc test). 


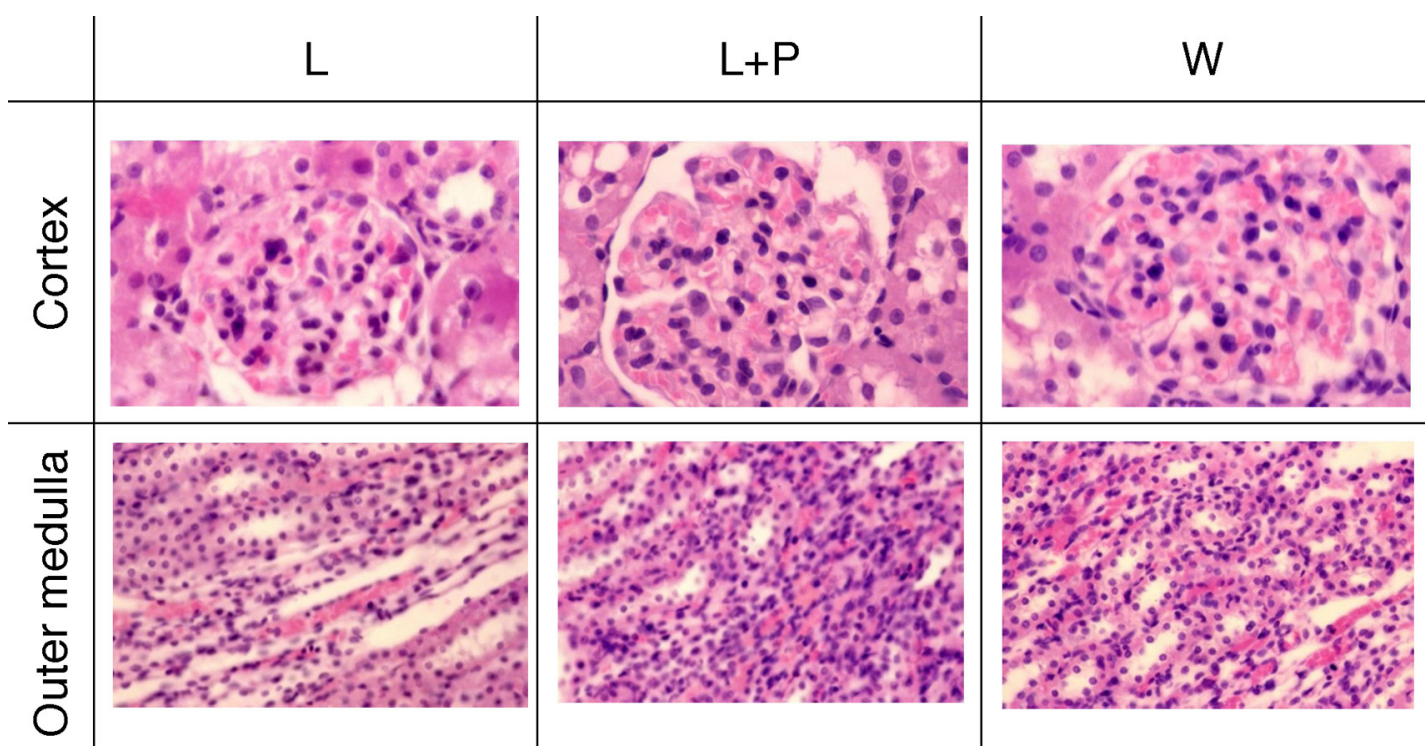

Fig. 6. Renal tissue slices (haematoxylin-eosin); L - liposomes, $\mathrm{L}+\mathrm{P}-$ liposomes with APren-7, W - water solvent; magnification in the cortex $200 \times$; in the outer medulla $100 \times$.

the values for $\mathrm{L}, \mathrm{L}+\mathrm{P}$ and $\mathrm{W}$ groups expressed as per cent of the starting weight were almost identical. According to Maitani et al. [19] the liposomes composed of dipalmitoylphosphatidylcholine (DPPC) do not cause any changes per se in the rat's body weight after subcutaneous injection. To the best of our knowledge physiological effects of any PE analogue treatment has never been tested in animals before.

The profiles of water intake and urine excretion deserve some attention (Table 1), especially the observation that the four-week increment $(\Delta)$ of water intake was in the W group higher than in both liposome groups whereas the increment in urine output in the $\mathrm{W}$ group was the lowest. For some reason the liposome-treated rats were protected against any water retention showing a better balance of water intake and output compared to solvent-treated rats.

SBP tended to increase in all groups (Fig. 2), however, the changes were minor and physiologically meaningless. The increasing tendency may have been related to daily subcutaneous injections, blood sampling and the distress due to the tail cuff method of SBP measurement, which requires immobilization of animals; the prohypertensive role of such manoeuvres has been described before [12]. It is unlikely that the minor SBP changes could induce left ventricular hypertrophy, measured as LV/BW which is a sensitive index of hypertension or heart disease [7]. Nor did liposome treatment affect this index in some direct way: LV/BW values for all groups were in the normal range for normotensive Sprague-Dawley rats [10] and so were also the values of plasma osmolality, sodium concentration and blood haematocrit. On the whole, there were no signs indicating damage of the cardiovascular system.

Various drugs and active substances are known to cause a number of morphologic changes in renal structures, such as microvacuolization (vacuolar lesions) [23]; cell loss, tubular dilation or disruption of the brush border of proximal tubules [5], atrophy of glomeruli or patches of necrosis [22]. All these abnormalities are likely to impair renal function. However, inspection of renal tissue slices stained with haematoxylin-eosin did not reveal any damage that might be caused by administration of the tested substances; microscopic images of the renal cortex and medulla did not differ between groups.

Microalbuminuria (elevated urinary albumin excretion, UAE) is a good marker of kidney damage and malfunction, and is also considered as an early index of cardiovascular disease $[8,27,30]$. In the end of experiments the values (Fig. 3) were within the normal UAE range for healthy Sprague-Dawley rats (0-1 mg/day) [16,17], which speaks against any kidney or cardiovascular system dysfunction. Since UAE significantly increased in the $\mathrm{W}$ but not in $\mathrm{L}$ or $\mathrm{L}+\mathrm{P}$ group, one could speculate that liposomes possess some protective properties.

Nitric oxide (NO) is an important antioxidant signalling molecule, which plays a critical role in various biological processes, such as control of vascular tone, blood pressure, renal haemodynamic and excretion, as well as developmental functions $[3,13]$. The actual activity of NO, which is produced by nitric oxide synthases (NOS) in many tissues, can be estimated by measuring the excretion of its metabolites [28]. However, the excretion of nitrites/nitrates $\left(\mathrm{NO}_{\mathrm{x}}\right)$ was almost stable throughout experiments and did not depend on the treatment applied (Fig. 5). Bentinger et al. [2] suggested that other derivatives of polyisoprenoids (epoxides) exhibit some beneficial activity, possibly by increasing the cell antioxidant capacity due to the stimulation of the biosynthesis of coenzyme $\mathrm{Q}$ a molecule likely to protect nitric oxide against inactivation by free radicals [29]. However, in this study we found no indication of antioxidant properties of APren-7.

The newly designed liposomes containing APrens did not affect, after subcutaneous administration, the development and maturation, or the function of the cardiovascular and renal excretory system of normal Sprague-Dawley rats. Since, microalbuminuria was even lower in the two groups receiving liposomes compared to that receiving water solvent, one can speculate on some protective action of liposomes, a proposal which would require further investigation. In general, our results showed no explicit adverse influence of the newly designed liposomes. In particular, they were not found to cause any damage per se of the rats' cardiovascular or renal excretory system, therefore we find them suitable as a component of liposomal drug carriers.

\section{Conflict of interest}

All authors declare that there is no actual or potential conflict of interest.

\section{Funding}

This work was supported by the Polish National Cohesion Strategy innovative Economy [Grant No. UDA-POIG.01.03.01-14036/09]. 
The author has been supported with a scholarship from the European Social Fund, Human Capital Operational Programme.

\section{References}

[1] Allen TM, Cullis PR. Drug delivery systems: entering the mainstream. Science 2004;303:1818-22.

[2] Bentinger M, Tekle M, Brismar K, Chojnacki T, Swiezewska E, Dallner G. Polyisoprenoid epoxides stimulate biosynthesis of $\mathrm{CoQ}$ and inhibit cholesterol synthesis. J Biol Chem 2008;283:14645-53.

[3] Borgonio A, Witte K, Stahrenberg R, Lemmer B. Influence of circadian time, ageing, and hypertension on the urinary excretion of nitric oxide metabolites in rats. Mech Ageing Dev 1999;111:23-37.

[4] Duncan R, Vicent MJ, Greco F, Nicholson RI. Polymer-drug conjugates: towards a novel approach for the treatment of endocrine-related cancer. Endocr Relat Cancer 2005;12:189-99.

[5] Fenoglio C, Boncompagni E, Chiavarina B, Cafaggi S, Cilli M, Viale M. Morphological and histochemical evidence of the protective effect of procainamide hydrochloride on tissue damage induced by repeated administration of low doses of cisplatin. Anticancer Res 2005;25:4123-8.

[6] Filion MC, Phillips NC. Toxicity and immunomodulatory activity of liposoma vectors formulated with cationic lipids toward immune effector cells. Biochim Biophys Acta 1997;1329(2):345-56

[7] Gardin JM, Lauer MS. Left ventricular hypertrophy: the next treatable, silent killer? JAMA 2004;292(19):2396-8.

[8] Gerstein HC, Mann JFE, Yi Q, Zinman B, Dinneen SF, Hoogwerf B, et al. Albuminuria and risk of cardiovascular events, death, and heart failure in diabetic and nondiabetic individuals. JAMA 2001;286(4):421-6.

[9] Graham LP. Drugs and drug targets: an overview. An introduction to medicinal chemistry. 4th ed. New York: Oxford University Press; 2009. p. 1-14

[10] Haas GJ, McCune SA, Brown DM, Cody RJ. Echocardiographic characterization of left ventricular adaptation in a genetically determined heart failure rat model. Am Heart J 1995;130(4):806-11.

[11] Hattori Y, Suzuki S, Kawakami S, Yamashita F, Hashida M. The role of dioleoylphosphatidylethanolamine (DOPE) in targeted gene delivery with mannosylated cationic liposomes via intravenous route. J Control Release 2005;108:484-95

[12] Henry JP, Liu YY, Nadra WE, Qian CG, Mormede P, Lemaire V, et al. Psychosocial stress can induce chronic hypertension in normotensive strains of rats. Hypertension 1993;21:714-23.

[13] Herrera M, Garvin JL. Recent advances in the regulation of nitric oxide in the kidney. Hypertension 2005;45:1062-7.

[14] Jafari M, Soltani M, Naahidi S, Karunaratne DN, Chen P. Nonviral approach for targeted nucleic acid delivery. Curr Med Chem 2012;19(2):197-208.
[15] Kajimoto K, Yamamoto M, Watanabe M, Kigasawa K, Kanamura K, Harashima $\mathrm{H}$, et al. Noninvasive and persistent transfollicular drug delivery system using a combination of liposomes and iontophoresis. Int J Pharm 2011;403: 57-65.

[16] Kohei U, Kazo K, Osamu H, Norikuni K, Sumiya E. Acute and chronic effects of thromboxane $\mathrm{A}_{2}$ inhibition on the renal hemodynamics in streptozotocininduced diabetic rats. Kidney Int 1994:45:794-802.

[17] Lu L, Peng W, Wei W, Wang L, Chen Q, Shen W. Effects of atorvastatin on progression of diabetic nephropathy and local RAGE and soluble RAGE expressions in rats. Biomed Biotechnol 2011;12(8):652-9.

[18] Madeja Z, Rak M, Wybieralska E, Rozanski I, Masnyk M, Chmielewski M, et al. New cationic polyprenyl derivative proposed as a lipofecting agent. Acta Biochim Pol 2007;54(4):873-6.

[19] Maitani Y, Hazama M, Tojo H, Qi XR, Nagai T. Effects of orally administered liposomes with soybean-derived sterols and their glucosides on rat body weight. Biol Pharm Bull 1995;18(11):1551-5.

[20] Mishra GP, Bagui M, Tamboli V, Mitra AK. Recent applications of liposomes in ophthalmic drug delivery. J Drug Deliv 2011;14. http://dx.doi.org/10.1155/ 2011/863734. Article ID 863734.

[21] Namiki Y, Fuchigami T, Tada N, Kawamura R, Matsunuma S, Kitamoto Y, et al Nanomedicine for cancer: lipid-based nanostructures for drug delivery and monitoring. Acc Chem Res 2011;44(10):1080-93.

[22] Ravindra P, Bhiwgade DA, Kulkarni S, Rataboli PV, Dhume CY. Cisplatin induced histological changes in renal tissue of rat. J Cell Anim Biol 2010;4(7):108-11.

[23] Rossmann P, Rihova B, Strohalm J, Ulbrich K. Morphology of rat kidney and thymus after native and antibody-coupled cyclosporin A application (reduced toxicity of targeted drug). Folia Microbiol 1997;42(3):277-87.

[24] Samad A, Sultana Y, Aqil M. Liposomal drug delivery systems: an update review. Curr Drug Deliv 2007;4:297-305.

[25] Steel JC, Cavanagh HMA, Burton MA, Abu-Asab MS, Tsokos M, Morris JC, et al. Increased tumor localization and reduced immune response to adenovira vector formulated with the liposome DDAB/DOPE. Eur J Pharm Sci 2007;30(5):398-405.

[26] Swiezewska E, Danikiewicz W. Polyisoprenoids: structure, biosynthesis an function. Prog Lipid Res 2005;44:235-58.

[27] Tojo A, Kinugasa S. Mechanisms of glomerular albumin filtration and tubular reabsorption. Int J Nephrol 2012;9. http://dx.doi.org/10.1155/2012/481520. Article ID 481520.

[28] Tsikas D. Methods of quantitative analysis of the nitric oxide metabolites nitrite and nitrate in human biological fluids. Free Radic Res 2005;39(8):797-815.

[29] Wyman M, Leonard M, Morledge T. Coenzyme Q10: a therapy for hypertension and statin-induced myalgia? Cleve Clin J Med 2010;77(7):435-42.

[30] Xiaorui C, Yueteng C, Zhufang S. A competitive ELISA for albumin in rat urine. ] Immunoassay Immunochem 2004;25(1):81-9. 